ERRATA

\title{
Erratum to: Erectile Dysfunction Drug Receipt, Risky Sexual Behavior and Sexually Transmitted Diseases in HIV
}

Robert L. Cook, MD, MPH', Kathleen A. McGinnis, $M S^{2}$, Jeffrey H. Samet, $M D^{3}$, David A. Fiellin, MD", Maria C. Rodriguez-Barradas, MD ${ }^{5}$, Kevin L. Kraemer, MD, MSc ${ }^{6}$, Cynthia L. Gibert, MD, MSC 7 , R. Scott Braithwaite, MD, MSc, FACP ${ }^{8}$, Joseph L. Goulet, PhD, MS ${ }^{4,9}$, Kristin Mattocks, PhD, MPH', Stephen Crystal, PhD ${ }^{10}$, Adam J. Gordon, MD, MPH ${ }^{2,6}$,

Krisann K. Oursler, MD, ScM ${ }^{17}$, and Amy C. Justice, MD, $P h D^{4,9}$

'Departments of Epidemiology and Biostatistics and Medicine, University of Florida, Gainesville, FL, USA; ${ }^{2}$ Pittsburgh VA Healthcare System, Pittsburgh, PA, USA; ${ }^{3}$ Boston University, Boston, MA, USA; ${ }^{4}$ Yale University, New Haven, CT, USA; ${ }^{5}$ Michael E Debakey VA Medical Center and Baylor College of Medicine, Houston, TX, USA; ${ }^{6}$ University of Pittsburgh, Pittsburgh, PA, USA; ${ }^{7}$ Washington DC VAMC and George Washington University, Washington, DC, USA; ${ }^{8}$ New York University School of Medicine, New York, NY, USA; ${ }^{9}$ VA Connecticut Healthcare System, West Haven, CT, USA; ${ }^{10}$ Rutgers University, New Brunswick, NJ, USA; ${ }^{11}$ Baltimore VA and University of Maryland, Baltimore, MD, USA.

$\mathrm{J}$ Gen Intern Med 25(12):1383

DOI: $10.1007 / \mathrm{s} 11606-010-1492-9$

(c) Society of General Internal Medicine 2010

\section{Erratum to: J Gen Intern Med DOI 10.1007/s11606-009-1164-9}

T $\mathrm{n}$ the original publication, the surname of the fifth author 1 was misspelled. The correct spelling is Rodriguez-Barradas MC.

The online version of the original article can be found at http://dx.doi. org/10.1007/s11606-009-1164-9.

Published online August 22, 2010 